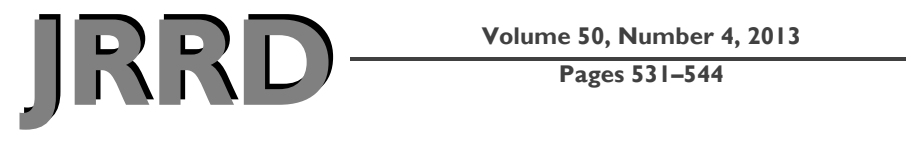

\title{
Bilateral electromyogram response latency following platform perturbation in unilateral transtibial prosthesis users: Influence of weight distribution and limb position
}

\author{
David Rusaw, PhD; ${ }^{1-2^{*}}$ Kerstin Hagberg, PhD; ${ }^{1}$ Lee Nolan, PhD; ${ }^{2-3}$ Nerrolyn Ramstrand, PhD ${ }^{2}$ \\ ${ }^{1}$ Institute for Clinical Sciences, Department of Orthopaedics, Sahlgrenska Academy, University of Gothenburg, \\ Gothenburg, Sweden; ${ }^{2}$ Department of Rehabilitation, School of Health Sciences, Jönköping University, Jönköping, \\ Sweden; ${ }^{3}$ Laboratory for Biomechanics and Motor Control, Department of Neuroscience, Karolinska Institutet and \\ GIH, Stockholm, Sweden
}

\begin{abstract}
Appropriate muscular response following an external perturbation is essential in preventing falls. Transtibial prosthesis users lack a foot-ankle complex and associated sensorimotor structures on the side with the prosthesis. The effect of this lack on rapid responses of the lower limb to external surface perturbations is unknown. The aim of the present study was to compare electromyogram (EMG) response latencies of otherwise healthy, unilateral, transtibial prosthesis users $(n=$ 23 , mean $+/-$ standard deviation $[\mathrm{SD}]$ age $=48+/-14 \mathrm{yr}$ ) and a matched control group $(n=23$, mean $+/-$ SD age $=48+/-$ $13 \mathrm{yr}$ ) following sudden support-surface rotations in the pitch plane (toes-up and toes-down). Perturbations were elicited in various weight-bearing and limb-perturbed conditions. The results indicated that transtibial prosthesis users have delayed responses of multiple muscles of the lower limb following perturbation, both in the intact and residual limbs. Weight-bearing had no influence on the response latency in the residual limb, but did on the intact limb. Which limb received the perturbation was found to influence the muscular response, with the intact limb showing a significantly delayed response when the perturbation was received only on the side with a prosthesis. These delayed responses may represent an increased risk of falling for individuals who use transtibial prostheses.
\end{abstract}

Key words: amputation, balance, electromyography, EMG, falling, lower limb, perturbation, prosthesis, postural response, transtibial.

\section{INTRODUCTION}

Postural stability is a dynamic process maintained by appropriate coordination of multiple physiological systems, including sensory, motor, and skeletal [1-3]. Pathological function of one or more of these physiological systems can be a contributing factor in falling [4-5]. Individuals with lower-limb amputations have reduced measures of postural stability [6-9] as determined by increased excursion of the center of pressure $(\mathrm{CoP})$ and sway amplitude [9] in the mediolateral [6-7] and anteroposterior directions. Moreover, they identify postural stability as an important criterion for functioning with a prosthesis [10], and they have been shown to fall more than age-matched

Abbreviations: $\mathrm{APR}=$ automatic postural response, $\mathrm{BF}=$ biceps femoris, $\mathrm{CoM}=$ center of mass, $\mathrm{CoP}=$ center of pressure, $\mathrm{EMG}=$ electromyogram, $\mathrm{GM}=$ gastrocnemius medialis, MANOVA $=$ multivariate analysis of variance, $\mathrm{SD}=$ standard deviation, $\mathrm{SSR}=$ support-surface rotation, $\mathrm{TA}=$ tibialis anterior, TTA = transtibial amputee, $\mathrm{VL}=$ vastus lateralis.

*Address all correspondence to David Rusaw, PhD; Department of Rehabilitation, School of Health Sciences, Jönköping University, Box 1026, 55111, Jönköping, Sweden; +46-(0)36-10-12-75; fax: +46-(0)36-10-11-80.

Email: david.rusaw@hhj.hj.se

http://dx.doi.org/10.1682/JRRD.2012.01.0017 
nondisabled individuals [11-12]. An understanding of how lower-limb prosthesis users initiate their response to maintain postural stability may provide important insights into how to prevent falls in this population.

Most of our current understanding of postural stability of individuals with an amputation has been provided by various measures of movement of the $\mathrm{CoP}$ on a stationary $[6-9,13-14]$ or unstable surface $[6,15-16]$. Several studies have demonstrated increased excursion of the $\mathrm{CoP}$ in the anteroposterior direction $[13,16]$ or both the anteroposterior and mediolateral directions [6-7,9,14]. Studies of individuals with lower-limb amputation have linked falling with movement of the CoP in the anteroposterior direction [8] and in individuals without amputation with a movement of the $\mathrm{CoP}$ in mediolateral plane [17-19]. Other researchers have investigated CoP and muscular response to catching a falling object [20] or lifting a leg [21]. In addition to increased CoP excursion, these studies have demonstrated that prosthesis users have an alteration in automatic muscular responses compared with nondisabled individuals.

An additional method of assessing postural stability is to actively challenge the postural control by introducing an external surface perturbation (rapidly moving the support surface) and assessing how the muscles required to maintain stability respond to this external stimulus [4]. With this method, electromyogram (EMG) signals from muscles are recorded and assessed based on the automatic postural response (APR) [4,22-23]. The APR is the first functionally significant physiological response to an external perturbation [24-25] and can have highly consistent temporal responses based on the type of perturbation: translational perturbations [22], rotational perturbations [23,25-26], and combinations of both [27-28]. Muscles that control the ankle can have APRs present as early as $100 \mathrm{~ms}$ [28-29], which is also the accepted minimum threshold for what is considered an APR [22]. However, APRs are influenced by many factors, including anxiety [30], previous experience [31], attention [32], and joint position [33]. In transtibial prosthesis users, APRs differ from previous investigations involving muscular response [20-21,34-35] in that they do not allow preemptive postural adjustments in anticipation of a motor task, but are mediated by feedback mechanisms and not under volitional control [36-37]. Support-surface rotations (SSRs) have been used to investigate APRs in young nondisabled participants [29-30,38-39], as well as in older individuals [26] and those with total knee arthroplasty [40]. The time from the first instance of motion of the support surface to onset of EMG activity is termed the response latency.

A major mediating factor in the generation of an APR is the movement of the center of mass (CoM). This is the result of multisensory contributions and not simply the result of local joint stimuli $[29,39]$. Among these sensory contributions, feedback in the form of cutaneous sensitivity from the plantar surface of the foot [41-43] and muscles at the ankle [44] is accepted as an important contributor to the multisensory regulation of APRs. The importance of this feedback becomes more critical as the balance task becomes more challenging [45], and a delay in the EMG response latency is indicative of a person's ability to respond to a balance threat and prevent a fall [46].

Prosthesis users lack sensory feedback distal to their amputation, and postural stability in the sagittal plane is reduced compared with nondisabled individuals [6]. Asymmetric feedback is subsequently important in optimizing the control of the intact lower limb [47], and the unilateral lower-limb sensory information received from the sound limb has an influence bilaterally in response to support-surface perturbations [48]. Individuals with a unilateral amputation have the removal of sensory structures in one limb, but postural reorganizations may occur in the prosthetic or intact limbs. We currently do not know how absence of one physiological ankle and the sensorimotor structures associated with the ankle affect the EMG response latency following SSRs in transtibial prosthesis users in the prosthetic and intact limbs.

Postural reorganization is a documented phenomenon in transtibial prosthesis users [20,35], and asymmetric weight-bearing is a commonly reported outcome $[9,13,15]$. Weight-bearing symmetry has often been used to evaluate interventions for prosthesis users [49-54]. In addition, it has been shown that prosthesis users have asymmetric postural reorganization, and their reliance on somatosensory afferent information increases with time after amputation [55]. We currently do not know how asymmetric weight-bearing affects EMG response latency in this population.

The aim of the current study was to investigate the EMG response latency in the intact and prosthetic limbs of unilateral transtibial prosthesis users following SSRs in the pitch plane (toes-up/toes-down). A secondary aim was to investigate how different weight-bearing scenarios on the intact and prosthetic limb affect the EMG response latencies. 


\section{METHODS}

\section{Participants}

Twenty-three transtibial amputee (TTA) prosthesis users (TTA group) were recruited to participate in the present study (mean \pm standard deviation $[\mathrm{SD}]$ age $=48 \pm$ $14 \mathrm{yr}$, height $=1.77 \pm 0.08 \mathrm{~m}$, and mass $=79 \pm 14 \mathrm{~kg}$ ). A group of 23 nondisabled control subjects (Control group) were also recruited (mean \pm SD age $=48 \pm 13 \mathrm{yr}$, height $=$ $1.77 \pm 0.08 \mathrm{~m}$, and mass $=80 \pm 13 \mathrm{~kg}$ ). Participant characteristics for both groups are given in Table 1. A power calculation, using EMG response latency times from a previous study [26], established that a minimum sample size of 23 was required to detect a statistically significant difference $(p<0.05)$ between two paired groups, given a statistical power of 0.8 and a true difference between the groups of $20 \mathrm{~ms}$. The TTA group was recruited based on having a unilateral transtibial amputation with no con- comitant health issues; no current issues regarding fit or function of the prosthesis including wounds, blisters, or skin breakdown; and at least 1 year of regular prosthesis use. All participants had a fiber-composite socket. Prosthetic feet varied between users (energy-storage-andreturn $=19$, multi-axis $=3$, single-axis $=1$ ) according to the classification described by Hafner [56]. The Control group was sex, age, height, and mass matched with the TTA group.

\section{Equipment}

Participants were requested to stand on a force platform (Pro Balance Master, Neurocom International Inc; Clackamas, Oregon) capable of SSRs in the pitch plane direction (dorsiflexion [toes-up] and plantarflexion [toesdown]), with an amplitude of $8^{\circ}$ and angular velocity of 50 $\%$ (angular acceleration 3,200\% $/ \mathrm{s}^{2}$ ) (Figure 1(a)). An eight-channel surface EMG system (Bagnoli-8, Delsys Inc; Boston, Massachusetts) recorded muscular response with

Table 1.

Participant characteristics. Transtibial amputee (TTA) group with sex, cause of amputation/limb deficiency, years since amputation/limb deficiency, height, mass, and age (mean \pm standard deviation $[\mathrm{SD}]$ of numerical data) provided. Residual limb length as defined by Persson and Liedberg [57], and prosthetic foot as defined by Hafner [56].

\begin{tabular}{|c|c|c|c|c|c|c|c|c|c|c|c|}
\hline \multicolumn{8}{|c|}{ TTA Group } & \multicolumn{4}{|c|}{ Control Group } \\
\hline Sex & Cause* & $\begin{array}{l}\text { Time } \\
(y r)^{*}\end{array}$ & $\begin{array}{l}\text { Height } \\
\text { (m) }\end{array}$ & $\begin{array}{c}\text { Mass } \\
(\mathrm{kg})\end{array}$ & $\begin{array}{l}\text { Age } \\
\text { (yr) }\end{array}$ & $\begin{array}{c}\text { Residual Limb } \\
\text { Length }\end{array}$ & $\begin{array}{c}\text { Prosthetic } \\
\text { Foot }\end{array}$ & Sex & $\begin{array}{c}\text { Height } \\
\text { (m) }\end{array}$ & $\begin{array}{c}\text { Mass } \\
(\mathbf{k g})\end{array}$ & $\begin{array}{l}\text { Age } \\
\text { (yr) }\end{array}$ \\
\hline $\mathrm{M}$ & Trauma & 8 & 1.78 & 74 & 46 & Ordinary & ESAR & $\mathrm{M}$ & 1.78 & 84 & 52 \\
\hline M & Infection & 5 & 1.80 & 67 & 27 & Ordinary & ESAR & M & 1.80 & 64 & 38 \\
\hline M & Trauma & 4 & 1.90 & 78 & 40 & Ordinary & ESAR & M & 1.93 & 78 & 40 \\
\hline M & Trauma & 12 & 1.84 & 97 & 65 & Long & ESAR & M & 1.84 & 108 & 63 \\
\hline M & Trauma & 3 & 1.86 & 82 & 53 & Ordinary & ESAR & M & 1.86 & 92 & 51 \\
\hline M & Trauma & 3 & 1.79 & 68 & 65 & Long & M-A & M & 1.79 & 76 & 62 \\
\hline $\mathrm{F}$ & Trauma & 33 & 1.59 & 64 & 60 & Long & ESAR & $\mathrm{F}$ & 1.62 & 62 & 52 \\
\hline M & Trauma & 2 & 1.78 & 87 & 51 & Ordinary & ESAR & M & 1.75 & 85 & 52 \\
\hline M & Trauma & 19 & 1.80 & 83 & 33 & Ordinary & M-A & M & 1.74 & 72 & 31 \\
\hline M & Trauma & 34 & 1.78 & 85 & 47 & Ordinary & ESAR & M & 1.84 & 85 & 43 \\
\hline M & Trauma & 3 & 1.78 & 88 & 72 & Long & ESAR & M & 1.75 & 78 & 72 \\
\hline M & Trauma & 44 & 1.80 & 91 & 63 & Ordinary & ESAR & M & 1.81 & 84 & 63 \\
\hline M & Trauma & 5 & 1.70 & 76 & 49 & Ordinary & ESAR & M & 1.70 & 76 & 49 \\
\hline $\mathrm{F}$ & OS & 28 & 1.71 & 73 & 47 & Long & M-A & $\mathrm{F}$ & 1.68 & 66 & 47 \\
\hline M & Trauma & 12 & 1.80 & 112 & 26 & Long & SA & M & 1.85 & 102 & 34 \\
\hline M & Trauma & 21 & 1.78 & 81 & 37 & Long & ESAR & M & 1.75 & 80 & 37 \\
\hline $\mathrm{F}$ & Cong & 25 & 1.54 & 64 & 25 & Long & ESAR & $\mathrm{F}$ & 1.60 & 53 & 24 \\
\hline M & Trauma & 13 & 1.80 & 78 & 60 & Ordinary & ESAR & M & 1.82 & 87 & 59 \\
\hline $\mathrm{F}$ & Infection & 5 & 1.82 & 57 & 30 & Ordinary & ESAR & $\mathrm{F}$ & 1.80 & 70 & 27 \\
\hline $\mathrm{F}$ & Cong & 45 & 1.64 & 64 & 45 & Long & ESAR & $\mathrm{F}$ & 1.64 & 65 & 42 \\
\hline M & Throm & 8 & 1.79 & 60 & 56 & Long & ESAR & M & 1.82 & 80 & 59 \\
\hline M & Trauma & 3 & 1.85 & 88 & 51 & Long & ESAR & M & 1.88 & 90 & 53 \\
\hline M & Trauma & 19 & 1.76 & 101 & 62 & Long & ESAR & M & 1.72 & 95 & 59 \\
\hline$\overline{M e a n} \pm \mathrm{SD}$ & & $15.4 \pm 13.6$ & $1.77 \pm 0.08$ & $79.0 \pm 13.8$ & $48.2 \pm 13.8$ & & & & $1.77 \pm 0.08$ & $79.7 \pm 13.1$ & $48.2 \pm 12.6$ \\
\hline
\end{tabular}




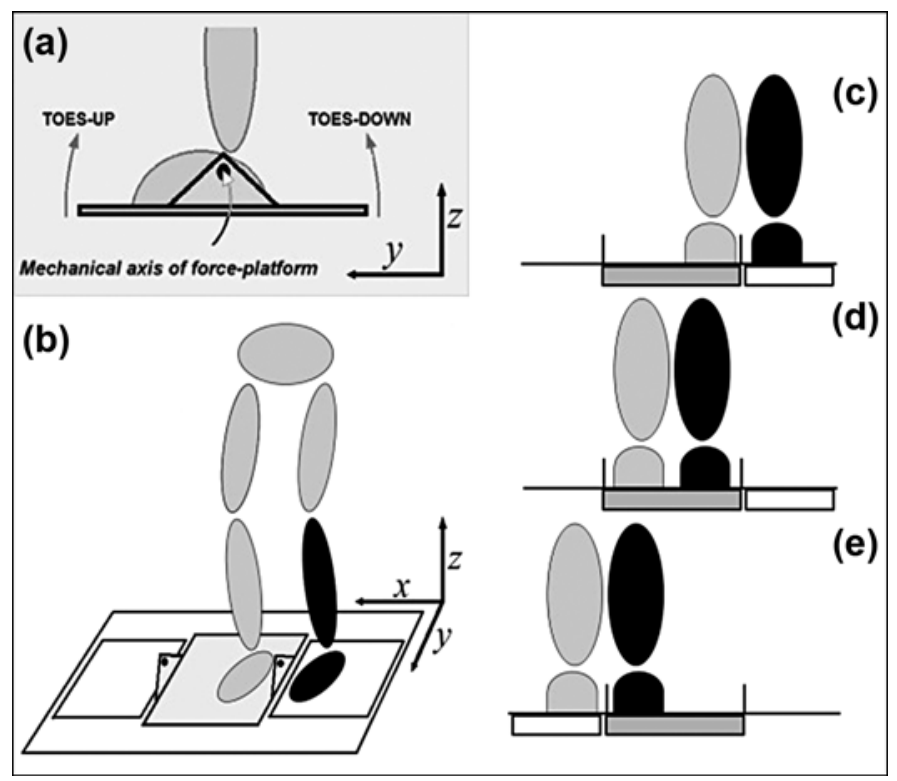

Figure 1.

Description of type of support-surface rotation and limb positions used. (a) Pitch plane surface rotations in toes-up and toes-down directions corresponding to rotations in sagittal plane $(y-z)$. Mechanical axis of force platform denoted in (b). (b) Standing orientation on support surface. White support surface is levelmounted scale used to monitor weight distribution during testing protocol. Three coordinate directions $(x-y-z)$ corresponding to (mediolateral-anteroposterior-superoinferior), with arrows corresponding to "positive" direction. (c)-(e) Standing position on platform and three limb-position scenarios. (c) Intact limb (gray) on force platform (also marked as gray), (d) both limbs on force platform, and (e) prosthetic limb (black) on force platform.

rectangular $(41 \times 20 \times 5 \mathrm{~mm})$, single-differential, surfacemounted, silver EMG sensors with an intra-electrode distance of $10.0 \mathrm{~mm}$ (Bagnoli DE-2.1, Delsys Inc). Motion analysis equipment (Qualysis, AB; Gothenburg, Sweden) was used to identify platform movement. In order for the weight-bearing distributions and $\mathrm{CoP}$ positions to be monitored in real-time by both the participant and the investigator, a computer screen display and digital scales were used. The computer screen conveyed CoP position with a visible cursor, and the digital scale (EKS International Inc; Gislaved, Sweden) conveyed weight distribution. The scale was mounted at the same vertical level as the force platform, lateral to the force platform (Figure 1). Display screens were mounted at eye level, $1 \mathrm{~m}$ in front of participants.

\section{Data Acquisition}

Raw EMG signals were first amplified (gain 1,000) and then band-pass analog filtered between 20 and $450 \mathrm{~Hz}$ prior to sampling at $1,000 \mathrm{~Hz}$. Detection characteristics of the EMG signal included an input impedance $>10^{15} \Omega / 0.2 \mathrm{pF}$, a common-mode rejection ratio of $92 \mathrm{~dB}$, and root-meansquared referred to the input noise of $1.2 \mathrm{uV}$. The $\mathrm{z}$-component data from four force transducers under the force platform were sampled at $1,000 \mathrm{~Hz}$. Motion-analysis data were simultaneously collected with an eight-camera motion analysis system (Qualysis $\mathrm{AB}$ ) at $500 \mathrm{~Hz}$ using four reflective markers placed on the force platform to identify perturbation onset. Markers were placed at the corners of the force platform (two anteriorly and two posteriorly) at distances of $30 \mathrm{~cm}$ and $20 \mathrm{~cm}$, respectively, from the mechanical axis of the force platform (Figure 1).

A series of SSRs in the pitch plane were conducted with the participant standing in each of three limbperturbed scenarios (Figure 1): (c) only intact foot on the platform (Intact), (d) both feet on the platform (Both), and (e) only prosthesis on the platform (Prosth). Within each of the limb positions, the participant was instructed to shift his or her body weight to provide three weightbearing scenarios: 50 percent weight distribution (Equal), reduced to 25 percent on the limb of interest (Reduced), and increased to 75 percent on the limb of interest (Increased) (Figure 1).

Surface EMG electrodes were placed over the muscles of interest as recommended by the Seniam guidelines [58]. Prior to electrode placement, we prepared the skin by shaving the hair and cleaning the skin with isopropyl alcohol at appropriate locations. For the TTA group, electrodes were placed over the tibialis anterior (TA) and gastrocnemius medialis (GM) muscles on the nonamputated limb and bilaterally on the vastus lateralis (VL) and biceps femoris (BF). For the Control group, electrodes were placed bilaterally over the TA, GM, VL, and BF. Participants were fitted with a harness suspended from the ceiling above the force platform in case of a fall. Instructions were given to maintain foot position and avoid leaning or otherwise changing body posture throughout the testing protocol. The same type of shoes was provided for all participants to eliminate the confounding factor of variations in shoe design [59]. Participants in the TTA group wore their currently functioning prosthesis.

Prior to having participants stand on the force platform, we established the 25/50/75 percent of body-mass distributions on an individual basis. This was done by having the participant stand on the digital scale mounted 
laterally from the force platform. The participant stood stationary with all of the equipment donned and an investigator read the results of the digital display. The 25/50/75 percent mass distributions were then calculated. When the participant stood with both feet on the force platform, the mediolateral mass distribution goals ( $x$-direction) were visualized by placing markings on the computer screen that had been predetermined to identify the locations that corresponded with the $25 / 50 / 75$ percent mass distributions. Participants were able to attain these goals by viewing in real-time the digital weight display in front of them.

Once mass distribution goals were determined, participants moved to the force platform, where foot position was established by placing the anatomical ankles at the mechanical axis of the force platform (Figure 1). For the TTA group, the intact ankle was aligned with the mechanical axis and the anteroposterior prosthetic limb foot position was then matched to the intact foot. The participants were then requested to stand upright facing the computer screen and to find their most comfortable standing position. In this posture, the investigator noted the position of the CoP in the anteroposterior direction by placing a horizontal mark on the computer screen in front of the participant. The participant was instructed that this was the anteroposterior "goal" position and was provided 1 to 2 min to practice shifting his or her body weight anteroposteriorly, following the $\mathrm{CoP}$ cursor on the computer screen, and maintaining the cursor position on the horizontal mark. Then the participant practiced mediolateral weight-shifting to the predetermined goals $(25 / 50 /$ $75 \%$ ). Using the digital display from the scale, the participant then immediately practiced shifting his or her body weight $(1-2 \mathrm{~min})$ in the mediolateral direction $(x$-direction) $(25 / 50 / 75 \%)$, while maintaining the anteroposterior goal position ( $y$-direction). Participants were deemed ready to continue when they could maintain the anteroposterior position of the $\mathrm{CoP}$ while shifting the $\mathrm{CoP}$ to each of the mediolateral goal positions. This never took longer than the given allowed practice time (maximum 4 min for anteroposterior and mediolateral). Finally, a practice session consisting of three to five SSRs was conducted in which both anteroposterior and mediolateral goals were maintained. Using a webcam, the investigator was able to verify in real time the CoP and weight distribution and verbally correct if the participant was not appropriately positioned. SSRs were not initiated until correct CoP position in the anteroposterior direction and correct weight distribution, as indicated by the digital display from the scale, were attained. Participants were reminded throughout the testing protocol to remain in an upright standing posture prior to the perturbation and to remain focused on the CoP on the computer screen in front of them. They were instructed to, to the best of their ability, resist the elicited perturbation and remain standing after the platform rotation.

A total of 99 trials was conducted: 33 trials for each of the limb-perturbed scenarios (Intact, Prosth, Both), with each of these scenarios further subdivided into 3 groups of 11 weight-distribution trials (Figure 2). Groups of 11 trials were broken into 5 for each direction (toes-up/ toes-down), with the first trial being discarded because of high variability associated with this trial [31]. Data collection began approximately $1 \mathrm{~s}$ before the platform moved and continued for a total data collection time of $8 \mathrm{~s}$. A random delay of between 10 and $15 \mathrm{~s}$ was inserted between the trials to prevent the participant from being able to anticipate the perturbation. To offset the effects of fatigue, a longer seated rest $(5-10 \mathrm{~min})$ was given between the limb-perturbed scenarios (A-C in Figure 2)

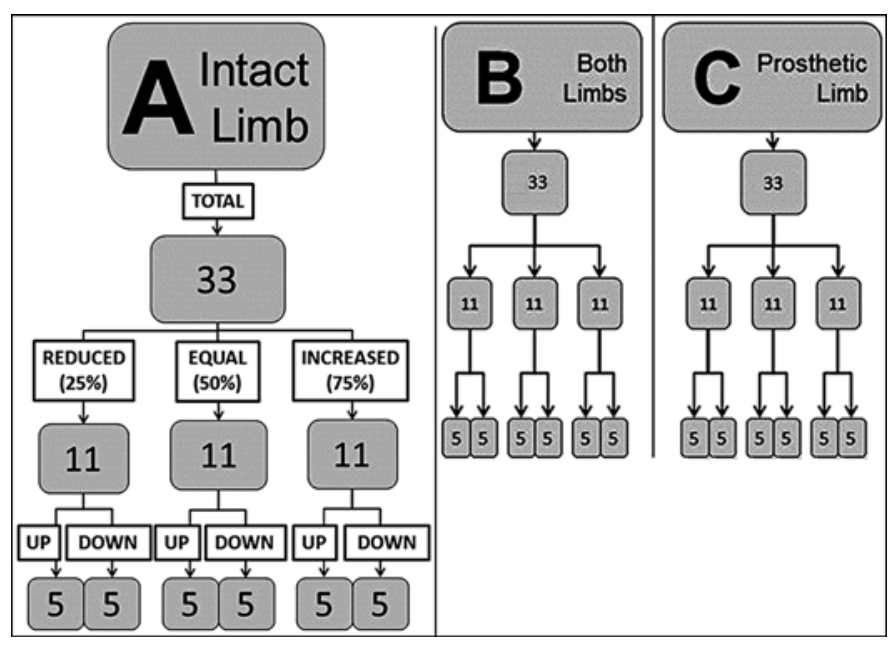

Figure 2.

Testing protocol for each of three limb positions (A, B, and C) for Intact, Both, and Prosthetic, respectively. Weight-bearing scenarios (Increased, Reduced, Equal) of limb of interest and direction (toes-up $=$ Up, toes-down = Down) for plantarflexion/ dorsiflexion stimulus direction of support-surface rotation. As each trial was randomized on three levels (limb position, weight distribution, rotation direction), figure is summary of number of trials per condition and not representation of order of conditions. Eleven trials for each of weight-bearing conditions include first trial, which was removed from analysis, leaving ten trials remaining for analysis (five toes-up and five toes-down). 
similar to previous studies [26]. The total time from beginning of data collection to completion was approximately $60 \mathrm{~min}$. The order of the trials was randomized at three places: limb position, weight distribution, and rotation direction.

\section{Data Analysis}

Following analog-to-digital conversion, the digital EMG signal was processed offline. EMG signals were full-wave rectified and low-pass filtered using a 4thorder Butterworth filter at a cutoff frequency of $100 \mathrm{~Hz}$ (slope of $24 \mathrm{~dB} /$ octave). Onset of SSR was first established by extracting the $z$-component (vertical) of the unfiltered three-dimensional position data for one marker located $30 \mathrm{~cm}$ anteriorly from the mechanical axis of the support surface. A moving capture window of $100 \mathrm{~ms}$ progressed through the data and designated platform motion as the first instance the $z$-component of the marker deviated 3 SDs from the preceding $100 \mathrm{~ms}$. Using this instance of platform movement, we determined EMG response latency offline by averaging the background EMG activity for each trial for the $100 \mathrm{~ms}$ immediately prior to the SSR. A response was then determined when an EMG response deviated 3 SD from the mean of the response during the background period and remained for a period of at least $10 \mathrm{~ms}$.

Prior to export for analysis, the data were prescreened to determine the trials in which the participants had an appropriate weight-bearing distribution. The pooled $z$-component data from all force transducers located in the rotatable force platform were summed to determine the weight being transmitted to the limb of interest. Trials were excluded if the participant's weight distribution deviated greater than \pm 5 percent of the intended weight distribution (25/50/75\%).

\section{Statistical Analysis}

Statistical analysis was performed using IBM SPSS Statistics, v. 19.0.0 (IBM; Armonk, New York). A Shapiro-Wilk test showed the data to be normally distributed. Paired $t$-tests showed no statistically significant difference between the dominant and nondominant sides of the Control group. For this reason, Control group data used in analysis are a pooled combination of both sides.

Two three-way multivariate analyses of variance (MANOVAs) were conducted to address the aims of the

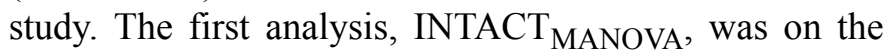
intact limb of the prosthesis users and the combined val- ues for both limbs of the control participants. The second analysis, PROSTH $\mathrm{MANOVA}_{\mathrm{M}}$, was on the prosthetic limb using the thigh (VL and BF) of the amputated limb with the corresponding combined signals of the control participants. For all analyses, "Group" refers to TTA vs Control, "Limb-perturbed" refers to the position of the limb of interest (intact or prosthetic) in relation to the force platform (On/Off/Both), and "Weight" refers to the weight distributions $(25 / 50 / 75 \%)$.

The INTACT MANOVA $_{\text {ad }}$ three independent variables (Group, Limb-perturbed, Weight) and eight dependent variables as bilateral EMG response latency of each of the four EMG channels (GM, TA, VL, BF) in two directions (toes-up, toes-down). The PROSTH $\mathrm{PANOVA}_{\text {MANO }}$ had three independent variables (Group, Limb-perturbed, Weight) and four dependent variables as EMG response latency of each of the two EMG channels (VL, BF) in two directions (toes-up, toes-down). Bonferroni post hoc tests were conducted where appropriate. Confidence intervals of the group main effects are presented. Statistical significance was determined using a critical alpha level of 0.05 for all tests.

Descriptive statistics were graphed using the pooled data for EMG response latency (On/Off/Both) from each muscle (GM, TA, VL, BF) and limb (intact and prosthetic) to describe the temporal activation of muscle responses across the lower limb.

\section{RESULTS}

Two participants in the Control group and one participant in the TTA group were unable to complete the entire testing protocol. The two Control group participants cited visual discomfort, and the TTA participant cited physical discomfort in the residual limb with increased weight-bearing. In all these cases, participants completed 88 of 99 trials, with the remaining 11 not included in statistical analysis.

\section{Intact Limb}

The results of the INTACT MANOVA $_{\text {showed a statis- }}$ tically significant main effect for each of the independent variables (Group, Limb-perturbed, Weight).

The statistically significant main effect for Group (TTA vs Control) (Table 2) was in the GM muscle in the toes-up direction $(p=0.02)$. The differences indicated increased mean EMG response latency for the TTA group 
Table 2.

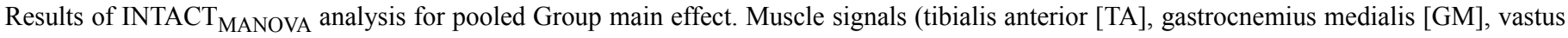
lateralis [VL], biceps femoris [BF]), support-surface rotation direction (toes-up = Up, toes-down = Down), Group (TTA vs Control), mean EMG response latency and difference in EMG latency times between groups (TTA vs Control), 95 percent confidence interval (CI) of mean EMG response latency and mean difference between groups (TTA vs Control), and $p$-values for pooled-group main effect presented.

\begin{tabular}{|c|c|c|c|c|c|c|c|}
\hline Muscle & Direction & Group & $\begin{array}{l}\text { Mean Latency } \\
\text { (ms) }\end{array}$ & 95\% CI & $\begin{array}{c}\text { Mean Difference } \\
\text { (TTA-Control) }\end{array}$ & $\begin{array}{l}95 \% \text { CI for } \\
\text { Difference }\end{array}$ & $p$-Value \\
\hline \multirow[t]{4}{*}{$\overline{\mathrm{TA}}$} & Up & TTA & 152 & 137 to 167 & 14 & -6 to 34 & 0.16 \\
\hline & & Control & 166 & 153 to 178 & & & \\
\hline & Down & TTA & 137 & 112 to 162 & 30 & -3 to 63 & 0.07 \\
\hline & & Control & 107 & 86 to 128 & & & \\
\hline \multirow[t]{4}{*}{ GM } & Up & TTA & 182 & 140 to 224 & 66 & 10 to 121 & $0.02 *$ \\
\hline & & Control & 116 & 80 to 152 & & & \\
\hline & Down & TTA & 181 & 159 to 202 & 8 & -21 to 37 & 0.60 \\
\hline & & Control & 189 & 170 to 207 & & & \\
\hline \multirow[t]{4}{*}{ VL } & Up & TTA & 220 & 190 to 249 & 14 & -24 to 52 & 0.47 \\
\hline & & Control & 206 & 181 to 231 & & & \\
\hline & Down & TTA & 130 & 113 to 146 & 9 & -12 to 31 & 0.40 \\
\hline & & Control & 121 & 107 to 134 & & & \\
\hline \multirow[t]{4}{*}{$\mathrm{BF}$} & Up & TTA & 179 & 137 to 221 & 38 & -17 to 93 & 0.17 \\
\hline & & Control & 141 & 105 to 177 & & & \\
\hline & Down & TTA & 193 & 164 to 222 & 15 & -23 to 53 & 0.43 \\
\hline & & Control & 178 & 153 to 202 & & & \\
\hline
\end{tabular}

(182 ms) compared with the Control group (116 ms). No statistically significant interaction effect was found for the remaining variables (Table 2).

The significant main effect for Limb-perturbed $(\mathrm{On} /$ Off/Both) was in the VL muscle in the toes-down direction. The statistically significant differences were between On $(98 \mathrm{~ms})$ and Off $(147 \mathrm{~ms})(p=0.006)$ and On $(98 \mathrm{~ms})$ and Both $(130 \mathrm{~ms})(p=0.03)$. There was one statistically significant interaction effect between Group and Limb-perturbed $(p=0.02)$, indicating the EMG response latency for the VL muscle was increased for the TTA group (195 ms) compared with the Control group (126 $\mathrm{ms}$ ) in the Off position (Figure 3).

The statistically significant main effect for Weight (Increased, Reduced, Equal) was in the VL muscle in the toes-down direction. These differences were between Increased $(100 \mathrm{~ms})$ and Reduced $(138 \mathrm{~ms})(p=0.03)$ and Increased $(100 \mathrm{~ms})$ and Equal $(137 \mathrm{~ms})(p=0.009)$. No statistically significant interaction effect was found for the remaining variables (Table 2).

\section{Prosthetic Limb}

The results of the PROSTH $\mathrm{PANOVA}_{\text {A }}$ showed a statistically significant main effect for the Group (TTA vs
Control) variable. The significant difference was in the BF muscle in the toes-up direction $(p=0.02)$, indicating increased EMG response latency for the TTA group (180 $\mathrm{ms})$ compared with the Control group (129 ms). No statistically significant interaction effect was found for the remaining variables (Table 3 ).

All other comparisons for main effect (Limbperturbed and Weight) were not statistically significant.

\section{Temporal Activation}

The pooled data for EMG response latency (On/Off/ Both) from each muscle (GM, TA, VL, BF) and limb (intact and prosthetic) indicate a slower reaction for the TTA group compared with the Control group (Figure 4).

\section{DISCUSSION}

The aim of this study was to evaluate the role limb position and weight-bearing play on EMG response latency following SSRs in the pitch plane on the prosthetic and intact limbs of otherwise healthy transtibial prosthesis users. There was significantly increased latency for both the intact and prosthetic limbs of the 


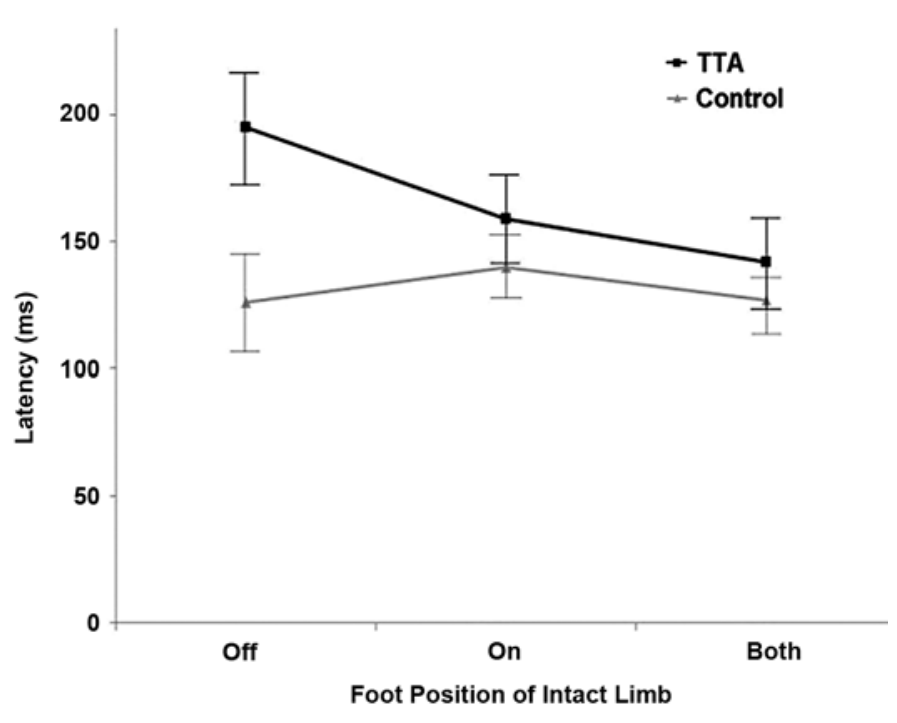

Figure 3.

Electromyogram (EMG) response latency (milliseconds) for vastus lateralis muscle in toes-down direction separated by group (transtibial amputee [TTA] or Control) and limb position (On/Off/Both). Significant interaction effect (group $x$ limb position; $p=0.02$ ) showed an increased EMG response latency for TTA group compared with Control group for Off variable.

TTA group when compared with the Control group. In the intact limb, the TTA group had increased EMG response latency in the GM muscle during toes-up rotations and in the VL muscle during toes-down rotations of the support surface. In the residual limb, the TTA group had increased EMG response latency in the BF muscle during toes-up rotations of the support surface.
In the toes-up direction, the GM muscle of the TTA group had significantly increased pooled mean latency (TTA group $=182 \mathrm{~ms}$, Control group $=116 \mathrm{~ms}$ ) regardless of weight distribution or limb position. This is of interest as a toes-up rotation of the TTA group's intact ankle is not anatomically different from the Control group. This indicates an influence functionally unrelated to the position of the limb as there was no interaction effect of limb-perturbed. As prosthesis users lack sensory information from the ankle about rotation of the support surface, one would expect increased EMG response latency in the GM muscle of the sound limb in the Off condition (only prosthesis receives perturbation). Yet, regardless of position, the TTA group had increased latency in the intact limb. Bilateral sensory changes $[14,60]$ and postural reorganization [55] previously shown in transtibial prosthesis users may be factors influencing this delayed EMG response in the intact limb. Given that the stretch reflex of the ankle can elicit an EMG response within $40 \mathrm{~ms}$ of perturbation, the results suggest there was no spinal reflex elicited for either of the groups. Many of the responses were around the 100 ms threshold for APRs [22], indicating the platform perturbation was of sufficient magnitude to fulfill the research aims of this investigation.

When the intact foot was on the force platform, the VL muscle of both groups (intact limb of TTA group) had significantly decreased pooled mean EMG onset latency in the toes-down direction $(\mathrm{On}=98 \mathrm{~ms})$ compared with each of the other two limb-perturbed conditions (Off =

Table 3.

Results of PROSTH $\mathrm{MANOVA}_{\mathrm{A}}$ analysis for pooled-group main effect (Group). Muscle signals (vastus lateralis [VL], biceps femoris [BF]), supportsurface rotation direction (toes-up $=\mathrm{Up}$, toes-down $=$ Down), group (transtibial amputee [TTA], Control), mean electromyogram $(\mathrm{EMG})$ response latency and difference of EMG response latency between groups (TTA vs Control), 95 percent confidence interval (CI) of mean EMG response latency and mean difference between groups (TTA vs Control), and $p$-values for pooled-group main effect presented.

\begin{tabular}{|c|c|c|c|c|c|c|c|}
\hline Muscle & Direction & Group & $\begin{array}{c}\text { Mean Latency } \\
\text { (ms) }\end{array}$ & 95\% CI & $\begin{array}{l}\text { Mean Difference } \\
\text { (TTA-Control) }\end{array}$ & $\begin{array}{l}\text { 95\% CI for } \\
\text { Difference }\end{array}$ & $p$-Value \\
\hline & & Control & 210 & 185 to 235 & & & \\
\hline & & Control & 119 & 107 to 132 & & & \\
\hline \multirow[t]{2}{*}{$\mathrm{BF}$} & Up & TTA & 180 & 146 to 214 & 51 & 7 to 94 & $0.02^{*}$ \\
\hline & & Control & 191 & 170 to 212 & & & \\
\hline
\end{tabular}

*Indicates significant difference between TTA and Control group.

MANOVA = multivariate analysis of variance. 


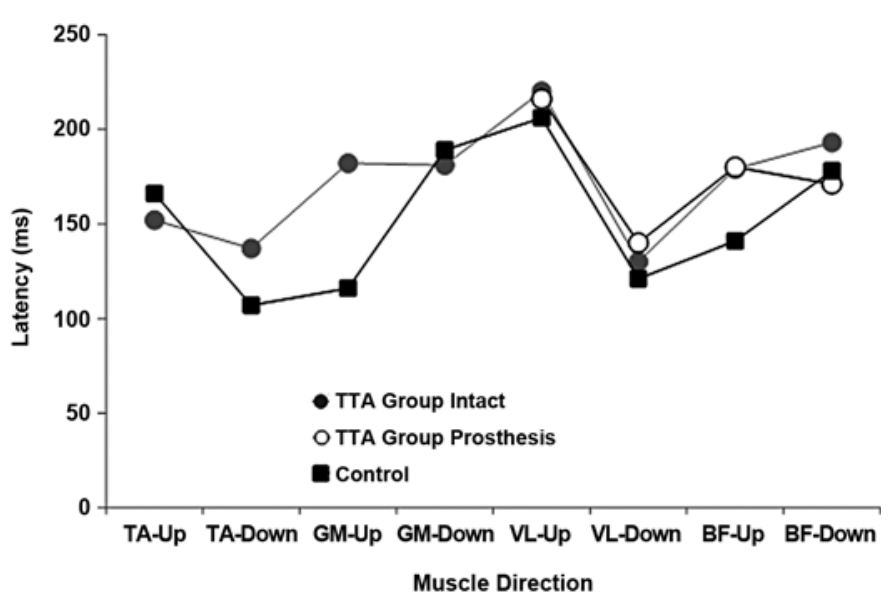

Figure 4.

Electromyogram (EMG) response latency (milliseconds) for each muscle from distal to proximal (left to right) for transtibial amputee (TTA) group (gray circle, intact limb; white circle, prosthetic limb) and control group (black square) for each muscle (tibialis anterior [TA], gastrocnemius medialis [GM], vastus lateralis [VL], biceps femoris [BF]) and direction (Up, Down).

$147 \mathrm{~ms}$, Both $=130 \mathrm{~ms}$ ). The significant interaction effect between group and limb-perturbed indicates the groups responded differently within the limb-perturbed condition. In the toes-down SSR, the TTA group had increased EMG response latency of the VL of the intact limb when the SSR was received with only the prosthesis on the force platform (Off) $($ TTA group $=195 \mathrm{~ms}$, Control group $=126 \mathrm{~ms}$ ) (Figure 3). A toes-down SSR forces the body's CoM anteriorly [43], and an increased EMG response latency on the intact limb could be due to a delayed movement of the CoM following the perturbation when the stimulus is through the prosthesis. It could also be due to alterations in local stimuli in the remaining structures of the residual limb $[3,29,43]$. Although this demonstrates a clear influence of the prosthetic side on response latencies in transtibial prosthesis users, further research is necessary to determine to what extent each of the factors ( $\mathrm{CoM}$ displacement and local joint stimuli) contributes to the differences. As the mechanical properties of prosthetic feet vary greatly [61], it is possible different prosthetic feet could lead to altered response latencies.

The TTA group also demonstrated differences in their EMG response latency in the residual limb. The difference identified was an increased latency of the BF muscle during a toes-up perturbation (TTA group $=180 \mathrm{~ms}$,
Control group $=129 \mathrm{~ms}$.). Voluntary knee flexion during toes-up rotations of the support surface is known to shorten the latency of the BF muscle in nondisabled individuals [33]. This was not the case for the TTA group, and EMG response latencies were longer than in the Control group. This is particularly interesting because of the clinically normal practice of preflexing the prosthetic socket. This is done to provide an increased vertical loading area within the socket and to preload the knee extensors of the prosthetic limb to increase their effectiveness in controlling knee-flexion during gait [62-63]. As the knee is generally more flexed in the residual limb than the Control group one must wonder why the TTA group does not have the same shortening of latency in the BF muscle that nondisabled individuals have [33]. Oude Nijhuis et al. showed that during toes-up rotation perturbations, there is a destabilizing effect that requires a compensatory strategy to prevent falling that includes earlier activation of muscle responses [33]. They also identified a role between knee flexion and the ankle torques produced following toes-up perturbation. They found voluntary knee flexion delayed the onset of knee flexion in response to the perturbation and eliminated the unloading activity of soleus and anterior tibialis. We cannot draw direct connections to our results as we did not analyze kinematic data, but the connection between knee flexion angles, ankle torques, and EMG response latency is a possible explanation for our results. As the TTA group lacks normal dorsiflexion of the prosthetic ankle, the prosthetic foot exhibits increasing resistance to dorsiflexion as the angle of dorsiflexion increases [61].

The foot and ankle are thought to influence postural control $[41,43,45]$, and delayed EMG response of lowerlimb musculature following sudden perturbations is indicative of a person's ability to prevent a fall following a balance threat [46]. More proximal sensory structures have been shown to adequately compensate for these deficits in an individual who lacked lower-limb proprioception [28]. The reason the TTA group was not able to compensate for this (as evident by increased EMG response latency) could be that individuals with lowerlimb limb loss have not only an absence of sensory information but also a total sensorimotor deficit distal to the amputation. If more proximal structures are able to sense the movement, it is not automatically given that the response would be in the muscles of the lower limb; it may be seen in the trunk musculature [28]. It is not necessarily the case that proximal muscles would have 
altered EMG response latencies as the angular perturbations used in this investigation elicited different physiological responses to the translational perturbations used in previous work $[39,64]$. The current study was limited to investigating EMG response latency of the muscles of the lower limb. As prosthesis users have postural reorganization $[20,35,55]$, which is likely to affect other muscles than those of the lower limb, future studies are warranted to see whether there are more proximal structures that are able to mediate postural responses in this population. As complex interactions between both limbs are responsible for coordinated response [48] and persons with unilateral amputation have contralateral sensory changes following their amputation [60], it is possible that the sensory structures of the intact limb had an effect on the results. By exploring the sensory structures of the remaining limbs in more detail with validated tools (e.g., monofilament testing), it might be possible to identify the interaction between sensory acuity and bilateral postural response. This is an important area and future studies should explore this connection.

The reaction times for the TTA group were on average slower than the reaction times for the Control group. This is evident by an average delay of the reaction times in the TTA group by 15 to $20 \mathrm{~ms}$ across all muscles of the lower limb. The temporal pattern of proximal-to-distal still seems to fit with the temporal pattern of response referred to as the "ankle" strategy [22]. Though, the only one of these group comparisons (TTA vs Control) that was statistically significantly different was the GM muscle of the intact limb when the rotation of the platform was in the toes-up direction. The borderline latency for what is considered an APR is $\sim 100 \mathrm{~ms}$ [28-29] to $\sim 120$ ms [23], which typically occurs in the ankle first, and the thigh is delayed by $\sim 30 \mathrm{~ms}$. The threshold at which volitional control begins to influence the EMG response is $\sim 180 \mathrm{~ms}$, suggesting - with the exception of the latencies of the VL and TA muscles $(130 \mathrm{~ms}$ and $137 \mathrm{~ms}$, respectively) - that the TTA group had fewer APRs and had a substantially larger component of the EMG response mediated under volitional control. This suggests that when transtibial prosthetic users are subjected to perturbations in the pitch plane, they are at increased risk of falling compared with nondisabled individuals.

There are some other limitations in the current study. The generalizability of the results to the larger population of all prosthesis users is not possible. The selection of participants who were free from concomitant health issues means the external validity of the study is compromised. We must also acknowledge that there is an imbalance in the TTA group in the number of male and female participants (male: $n=18$; female: $n=5$ ). The TTA group wore their currently functioning prosthesis, and the types of feet were not consistent for all participants. There may be an influence by the type of prosthetic foot incorporated into the prosthesis, and further research is warranted to answer this relevant question.

Although all of the participants were transtibial prosthetic users, there were two individuals with congenital limb loss. Although not part of the original aim, these individuals' pooled results were analyzed separately to explore any differences that may have existed with the TTA group. In the intact limb, there were no clear differences between the TTA group and these two individuals. There were five response latencies that were shorter $($ mean $=24 \mathrm{~ms})$ and three that were increased (mean $=$ $18 \mathrm{~ms}$ ). There appeared to be no clear pattern, with the results spread equally throughout the toes-up and toesdown directions. For the prosthetic limb, there were shortened response latencies for all muscles compared with the TTA group in both the toes-up (mean $=52 \mathrm{~ms}$ ) and toesdown (mean $=40 \mathrm{~ms}$ ) rotations. These results suggest that this subsample of two individuals with congenital limb loss may have altered neurological responses to platform perturbations when compared with individuals who have had an amputation. Future research should explore these potential differences.

The testing protocol was controlled to accommodate for any potential learning effects that may have been present in the data. The randomization occurred at three levels: the limb-position of the individual, the weightbearing condition, and the direction of the platform rotation. In our methods, we discarded the first trial of each of the 11 trial blocks because of high variability [31], which may have offered additional information not given in the current analysis [65]. Future studies will include this important aspect in the analysis of postural response. A number of attempts were made to minimize any effect fatigue may have had on the results. This included multiple levels of randomization in the trial orders, mandated resting periods between testing blocks, and verbal reminders from the investigator during testing. We believe these efforts have limited the effects fatigue may have had on the results.

The significant differences in EMG response latency following SSRs observed in this investigation all occurred 
within $200 \mathrm{~ms}$ of the perturbation. Periods of $200 \mathrm{~ms}$ of surface EMG signal have been shown sufficient to identify modes of gait for the purposes of controlling externally powered prosthetic limbs [66]. As many of the EMG response latencies were under $200 \mathrm{~ms}$, the results suggest that it is technically possible to use the same technology to identify muscle synergies following perturbations in the same population. Rapid identification of muscle responses would enable prosthetic components to respond quickly (potentially prior to the $200 \mathrm{~ms}$ threshold for conscious control) to sudden balance threats and potentially prevent falls. Zhang et al. showed that during ambulation, prosthetic foot acceleration and EMG response latency were two variables that were highly accurate in identifying stumble reactions in transfemoral prosthesis users [67]. The authors suggest, although acceleration of the prosthetic foot identified the stumble sooner depending on type of perturbation, a combination of both acceleration and EMG signals greatly increased the accuracy of stumble identification. With further investigation, it would be possible to clarify whether similar results would be observed in situations in which the participants were not ambulating. Manufacturers of prosthetic components attempting to utilize the physiological response of lower-limb musculature to coordinate responses of these components (such as intelligent ankle systems) must take this physiological response into account. They must recognize that not only do prosthesis users have different responses compared with nondisabled individuals, the responses are also dependent on the side of interest. The prosthetic limb has reactions during these postural perturbations that cannot necessarily be used to predict what is happening at the other limb, at least in the length of times included in this study (<700 ms).

\section{CONCLUSIONS}

Transtibial prosthesis users have delayed responses of various muscles of the lower limb following pitch plane SSRs when compared with a group of nondisabled controls. These delayed responses were both in the intact limb and the residual limb. Weight-bearing had no influence on the response latency in the residual limb, but did on the intact limb. Limb position was found to influence the muscular response, with the intact limb showing a significantly delayed response when the perturbation was received only on the side with a prosthesis. These delayed EMG responses in transtibial prosthesis users may place them at increased risk of falling when subjected to an external balance threat.

\section{ACKNOWLEDGMENTS}

\section{Author Contributions:}

All authors contributed in the conception, design, critical analysis, and manuscript preparation.

Data collection: D. Rusaw.

Financial Disclosures: The authors have declared that no competing interests exist.

Funding/Support: This material is the result of work supported with resources of the Sveriges Ortopedingenjörs Förening (SOIF).

Additional Contributions: The authors wish to thank Kjell-Åke Nilsson, Jessica Crafoord, Maria Glemne, Dan Karlsson, and Prof. Björn Rydevik for their assistance in this study.

Institutional Review: All participants provided written consent and were advised they may withdraw from the study at any time without giving reason. Ethical approval for the study was granted by the Ethical Regional Review Board in Linköping, Sweden.

Participant Follow-Up: The authors do not plan to inform participants of the publication of this study.

\section{REFERENCES}

1. Peterka RJ. Sensorimotor integration in human postural control. J Neurophysiol. 2002;88(3):1097-1118. [PMID:12205132]

2. Peterka RJ, Loughlin PJ. Dynamic regulation of sensorimotor integration in human postural control. J Neurophysiol. 2004; 91(1):410-23. [PMID:13679407] http://dx.doi.org/10.1152/jn.00516.2003

3. Allum JH, Honegger F. Interactions between vestibular and proprioceptive inputs triggering and modulating human balance-correcting responses differ across muscles. Exp Brain Res. 1998;121(4):478-94. [PMID:9746156] http://dx.doi.org/10.1007/s002210050484

4. Horak FB, Henry SM, Shumway-Cook A. Postural perturbations: new insights for treatment of balance disorders. Phys Ther. 1997;77(5):517-33. [PMID:9149762]

5. Meyer PF, Oddsson LI, De Luca CJ. Reduced plantar sensitivity alters postural responses to lateral perturbations of balance. Exp Brain Res. 2004;157(4):526-36. [PMID:15029466] http://dx.doi.org/10.1007/s00221-004-1868-3

6. Buckley JG, O'Driscoll D, Bennett SJ. Postural sway and active balance performance in highly active lower-limb amputees. Am J Phys Med Rehabil. 2002;81(1):13-20. [PMID:11807327] http://dx.doi.org/10.1097/00002060-200201000-00004 
7. Hermodsson Y, Ekdahl C, Persson BM, Roxendal G. Standing balance in trans-tibial amputees following vascular disease or trauma: a comparative study with healthy subjects. Prosthet Orthot Int. 1994;18(3):150-58. [PMID:7724348]

8. Quai TM, Brauer SG, Nitz JC. Somatosensation, circulation and stance balance in elderly dysvascular transtibial amputees. Clin Rehabil. 2005;19(6):668-76.

[PMID:16180604]

http://dx.doi.org/10.1191/0269215505cr857oa

9. Isakov E, Mizrahi J, Ring H, Susak Z, Hakim N. Standing sway and weight-bearing distribution in people with below-knee amputations. Arch Phys Med Rehabil. 1992; 73(2):174-78. [PMID:1543414]

10. Legro MW, Reiber G, del Aguila M, Ajax MJ, Boone DA, Larsen JA, Smith DG, Sangeorzan B. Issues of importance reported by persons with lower limb amputations and prostheses. J Rehabil Res Dev. 1999;36(3):155-63. [PMID:10659798]

11. Miller WC, Deathe AB, Speechley M, Koval J. The influence of falling, fear of falling, and balance confidence on prosthetic mobility and social activity among individuals with a lower extremity amputation. Arch Phys Med Rehabil. 2001;82(9):1238-44. [PMID:11552197]

http://dx.doi.org/10.1053/apmr.2001.25079

12. Miller WC, Speechley M, Deathe B. The prevalence and risk factors of falling and fear of falling among lower extremity amputees. Arch Phys Med Rehabil. 2001; 82(8):1031-37. [PMID:11494181] http://dx.doi.org/10.1053/apmr.2001.24295

13. Rougier PR, Bergeau J. Biomechanical analysis of postural control of persons with transtibial or transfemoral amputation. Am J Phys Med Rehabil. 2009;88(11):896-903. [PMID:19661773] http://dx.doi.org/10.1097/PHM.0b013e3181b331af

14. Geurts AC, Mulder TW, Nienhuis B, Rijken RA. Dual-task assessment of reorganization of postural control in persons with lower limb amputation. Arch Phys Med Rehabil. 1991;72(13):1059-64. PMID:1741657]

15. Vanicek N, Strike S, McNaughton L, Polman R. Postural responses to dynamic perturbations in amputee fallers versus nonfallers: a comparative study with able-bodied subjects. Arch Phys Med Rehabil. 2009;90(6):1018-25. [PMID:19480879] http://dx.doi.org/10.1016/j.apmr.2008.12.024

16. Vrieling AH, van Keeken HG, Schoppen T, Otten E, Hof AL, Halbertsma JP, Postema K. Balance control on a moving platform in unilateral lower limb amputees. Gait Posture. 2008;28(2):222-28. [PMID:18207407] http://dx.doi.org/10.1016/j.gaitpost.2007.12.002

17. Buatois S, Gueguen R, Gauchard GC, Benetos A, Perrin PP. Posturography and risk of recurrent falls in healthy non-institutionalized persons aged over 65. Gerontology.
2006;52(6):345-52. [PMID:16905886]

http://dx.doi.org/10.1159/000094983

18. Norris JA, Marsh AP, Smith IJ, Kohut RI, Miller ME. Ability of static and statistical mechanics posturographic measures to distinguish between age and fall risk. J Biomech. 2005;38(6):1263-72. [PMID:15863111] http://dx.doi.org/10.1016/j.jbiomech.2004.06.014

19. Piirtola M, Era P. Force platform measurements as predictors of falls among older people - a review. Gerontology. 2006;52(1):1-16. [PMID:16439819] http://dx.doi.org/10.1159/000089820

20. Aruin AS, Nicholas JJ, Latash ML. Anticipatory postural adjustments during standing in below-the-knee amputees. Clin Biomech (Bristol, Avon). 1997;12(1):52-59. [PMID:11415672] http://dx.doi.org/10.1016/S0268-0033(96)00053-8

21. Viton JM, Mouchnino L, Mille ML, Cincera M, Delarque A, Pedotti A, Bardot A, Massion J. Equilibrium and movement control strategies in trans-tibial amputees. Prosthet Orthot Int. 2000;24(2):108-16. [PMID:11061197] http://dx.doi.org/10.1080/03093640008726533

22. Torres-Oviedo G, Ting LH. Muscle synergies characterizing human postural responses. J Neurophysiol. 2007;98(4): 2144-56. [PMID:17652413] http://dx.doi.org/10.1152/jn.01360.2006

23. Nashner LM, Cordo PJ. Relation of automatic postural responses and reaction-time voluntary movements of human leg muscles. Exp Brain Res. 1981;43(3-4):395-405. [PMID:7262232]

24. Nashner LM. Adapting reflexes controlling the human posture. Exp Brain Res. 1976;26(1):59-72. [PMID:964327] http://dx.doi.org/10.1007/BF00235249

25. Nashner LM, Woollacott M, Tuma G. Organization of rapid responses to postural and locomotor-like perturbations of standing man. Exp Brain Res. 1979;36(3):463-76. [PMID:477777] http://dx.doi.org/10.1007/BF00238516

26. Allum JH, Carpenter MG, Honegger F, Adkin AL, Bloem BR. Age-dependent variations in the directional sensitivity of balance corrections and compensatory arm movements in man. J Physiol. 2002;542(Pt 2):643-63.

[PMID:12122159] http://dx.doi.org/10.1113/jphysiol.2001.015644

27. Bloem BR, Allum JH, Carpenter MG, Honegger F. Is lower leg proprioception essential for triggering human automatic postural responses? Exp Brain Res. 2000;130(3):375-91. [PMID:10706436] http://dx.doi.org/10.1007/s002219900259

28. Bloem BR, Allum JH, Carpenter MG, Verschuuren JJ, Honegger F. Triggering of balance corrections and compensatory strategies in a patient with total leg proprioceptive loss. Exp Brain Res. 2002;142(1):91-107. 
[PMID:11797087]

http://dx.doi.org/10.1007/s00221-001-0926-3

29. Carpenter MG, Allum JH, Honegger F. Directional sensitivity of stretch reflexes and balance corrections for normal subjects in the roll and pitch planes. Exp Brain Res. 1999; 129(1):93-113. [PMID:10550507] http://dx.doi.org/10.1007/s002210050940

30. Carpenter MG, Frank JS, Adkin AL, Paton A, Allum JH. Influence of postural anxiety on postural reactions to multidirectional surface rotations. J Neurophysiol. 2004;92(6): 3255-65. [PMID:15295016] http://dx.doi.org/10.1152/jn.01139.2003

31. Keshner EA, Allum JH, Pfaltz CR. Postural coactivation and adaptation in the sway stabilizing responses of normals and patients with bilateral vestibular deficit. Exp Brain Res. 1987;69(1):77-92. [PMID:3501760] http://dx.doi.org/10.1007/BF00247031

32. Woollacott M, Shumway-Cook A. Attention and the control of posture and gait: a review of an emerging area of research. Gait Posture. 2002;16(1):1-14.

[PMID:12127181]

http://dx.doi.org/10.1016/S0966-6362(01)00156-4

33. Oude Nijhuis LB, Bloem BR, Carpenter MG, Allum JH. Incorporating voluntary knee flexion into nonanticipatory balance corrections. J Neurophysiol. 2007;98(5):3047-59. [PMID:17898137] http://dx.doi.org/10.1152/jn.01303.2006

34. Curtze C, Hof AL, Otten B, Postema K. Balance recovery after an evoked forward fall in unilateral transtibial amputees. Gait Posture. 2010;32(3):336-41. [PMID:20609587] http://dx.doi.org/10.1016/j.gaitpost.2010.06.005

35. Mouchnino L, Mille ML, Cincera M, Bardot A, Delarque A, Pedotti A, Massion J. Postural reorganization of weightshifting in below-knee amputees during leg raising. Exp Brain Res. 1998;121(2):205-14. [PMID:9696390] http://dx.doi.org/10.1007/s002210050453

36. Ting LH, van Antwerp KW, Scrivens JE, McKay JL, Welch TD, Bingham JT, DeWeerth SP. Neuromechanical tuning of nonlinear postural control dynamics. Chaos. 2009;19(2): 026111. [PMID:19566271] http://dx.doi.org/10.1063/1.3142245

37. Welch TD, Ting LH. A feedback model explains the differential scaling of human postural responses to perturbation acceleration and velocity. J Neurophysiol. 2009;101(6): 3294-3309. [PMID:19357335] http://dx.doi.org/10.1152/jn.90775.2008

38. Allum JH, Honegger F. A postural model of balance-correcting movement strategies. J Vestib Res. 1992;2(4):323-47. [PMID:1342406]

39. Ting LH. Dimensional reduction in sensorimotor systems: a framework for understanding muscle coordination of posture. Prog Brain Res. 2007;165:299-321.

\section{[PMID:17925254]}

http://dx.doi.org/10.1016/S0079-6123(06)65019-X

40. Gage WH, Frank JS, Prentice SD, Stevenson P. Organization of postural responses following a rotational support surface perturbation, after TKA: sagittal plane rotations. Gait Posture. 2007;25(1):112-20. [PMID:16580837] http://dx.doi.org/10.1016/j.gaitpost.2006.02.003

41. Kavounoudias A, Roll R, Roll JP. Foot sole and ankle muscle inputs contribute jointly to human erect posture regulation. J Physiol. 2001;532(Pt 3):869-78. [PMID:11313452] http://dx.doi.org/10.1111/j.1469-7793.2001.0869e.x

42. Do MC, Bussel B, Breniere Y. Influence of plantar cutaneous afferents on early compensatory reactions to forward fall. Exp Brain Res. 1990;79(2):319-24. [PMID:2323379] http://dx.doi.org/10.1007/BF00608241

43. Ting LH, Macpherson JM. Ratio of shear to load groundreaction force may underlie the directional tuning of the automatic postural response to rotation and translation. J Neurophysiol. 2004;92(2):808-23. [PMID:15084643] http://dx.doi.org/10.1152/jn.00773.2003

44. Nielsen JB, Sinkjaer T. Afferent feedback in the control of human gait. J Electromyogr Kinesiol. 2002;12(3):213-17. [PMID:12086816] http://dx.doi.org/10.1016/S1050-6411(02)00023-8

45. Meyer PF, Oddsson LI, De Luca CJ. The role of plantar cutaneous sensation in unperturbed stance. Exp Brain Res. 2004;156(4):505-12. [PMID:14968274] http://dx.doi.org/10.1007/s00221-003-1804-y

46. Robinovitch SN, Heller B, Lui A, Cortez J. Effect of strength and speed of torque development on balance recovery with the ankle strategy. J Neurophysiol. 2002; 88(2):613-20. [PMID:12163514]

47. Bunderson NE, Ting LH, Burkholder TJ. Asymmetric interjoint feedback contributes to postural control of redundant multi-link systems. J Neural Eng. 2007;4(3):234-45. [PMID:17873426] http://dx.doi.org/10.1088/1741-2560/4/3/009

48. Dietz V, Horstmann GA, Berger W. Interlimb coordination of leg-muscle activation during perturbation of stance in humans. J Neurophysiol. 1989;62(3):680-93. [PMID:2769353]

49. Summers GD, Morrison JD, Cochrane GM. Amputee walking training: a preliminary study of biomechanical measurements of stance and balance. Int Disabil Stud. 1988;10(1):1-5. [PMID:3391935] http://dx.doi.org/10.3109/09638288809164048

50. Duclos C, Roll R, Kavounoudias A, Roll JP, Forget R. Vibration-induced post-effects: a means to improve postural asymmetry in lower leg amputees? Gait Posture. 2007;26(4):595-602. [PMID:17236772] http://dx.doi.org/10.1016/j.gaitpost.2006.12.005 
51. Fan RE, Culjat MO, King CH, Franco ML, Boryk R, Bisley JW, Dutson E, Grundfest WS. A haptic feedback system for lower-limb prostheses. IEEE Trans Neural Syst Rehabil Eng. 2008;16(3):270-77. [PMID:18586606] http://dx.doi.org/10.1109/TNSRE.2008.920075

52. Fan RE, Culjat MO, King CH, Franco ML, Sedrak M, Bisley JW, Dutson EP, Grundfest WS. A prototype haptic feedback system for lower-limb prostheses and sensory neuropathy. Stud Health Technol Inform. 2008;132:115-19. [PMID:18391269]

53. Lee M-Y, Lin C-F, Soon K-S. Balance control enhancement using sub-sensory stimulation and visual-auditory biofeedback strategies for amputee subjects. Prosthet Orthot Int. 2007;31(4):342-52. [PMID:18050006] http://dx.doi.org/10.1080/03093640601058162

54. Sabolich JA, Ortega GM. Sense of feel of lower-limb amputees: a phase-one study. J Prosthet Orthot. 1994;6(2): 36-41. http://dx.doi.org/10.1097/00008526-199400620-00003

55. Geurts AC, Mulder TW, Nienhuis B, Rijken RA. Postural reorganization following lower limb amputation. Possible motor and sensory determinants of recovery. Scand J Rehabil Med. 1992;24(2):83-90. [PMID:1604266]

56. Hafner BJ. Clinical prescription and use of prosthetic foot and ankle mechanisms: a review of the literature. J Prosthet Orthot. 2005;17(4S):5-11. http://dx.doi.org/10.1097/00008526-200510001-00004

57. Persson BM, Liedberg E. A clinical standard of stump measurement and classification in lower limb amputees. Prosthet Orthot Int. 1983;7(1):17-24. [PMID:6856447]

58. Hermens HJ, Freriks B. The Seniam Project-Recommendations for sensor locations on individual muscles [Internet]. Enschede (the Netherlands): Seniam; 1997 [cited 2010 June 16]; Available from: www.seniam.org.

59. Robbins S, Waked E, Krouglicof N. Improving balance. J Am Geriatr Soc. 1998;46(11):1363-70. [PMID:9809757]

60. Kavounoudias A, Tremblay C, Gravel D, Iancu A, Forget R. Bilateral changes in somatosensory sensibility after unilateral below-knee amputation. Arch Phys Med Rehabil. 2005;86(4):633-40. [PMID:15827911] http://dx.doi.org/10.1016/j.apmr.2004.10.030

61. van Jaarsveld HW, Grootenboer HJ, de Vries J, Koopman HF. Stiffness and hysteresis properties of some prosthetic feet. Prosthet Orthot Int. 1990;14(3):117-24. [PMID:2095529]
62. Zahedi MS, Spence WD, Solomonidis SE, Paul JP. Alignment of lower-limb prostheses. J Rehabil Res Dev. 1986; 23(2):2-19. [PMID:3723422]

63. Chow DH, Holmes AD, Lee CK, Sin SW. The effect of prosthesis alignment on the symmetry of gait in subjects with unilateral transtibial amputation. Prosthet Orthot Int. 2006;30(2):114-28. [PMID:16990222] http://dx.doi.org/10.1080/03093640600568617

64. Allum JH, Honegger F. Synergies and strategies underlying normal and vestibulary deficient control of balance: implication for neuroprosthetic control. Prog Brain Res. 1993; 97:331-48. [PMID:8234759] http://dx.doi.org/10.1016/S0079-6123(08)62293-1

65. Oude Nijhuis LB, Allum JH, Borm GF, Honegger F, Overeem S, Bloem BR. Directional sensitivity of "first trial" reactions in human balance control. J Neurophysiol. 2009;101(6):2802-14. [PMID:19279150] http://dx.doi.org/10.1152/jn.90945.2008

66. Huang H, Kuiken TA, Lipschutz RD. A strategy for identifying locomotion modes using surface electromyography. IEEE Trans Biomed Eng. 2009;56(1):65-73.

[PMID:19224720] http://dx.doi.org/10.1109/TBME.2008.2003293

67. Zhang F, D’Andrea SE, Nunnery MJ, Kay SM, Huang H. Towards design of a stumble detection system for artificial legs. IEEE Trans Neural Syst Rehabil Eng. 2011;19(5): 567-77. [PMID:21859635] http://dx.doi.org/10.1109/TNSRE.2011.2161888

Submitted for publication January 27, 2012. Accepted in revised form October 11, 2012.

This article and any supplemental material should be cited as follows:

Rusaw D, Hagberg K, Nolan L, Ramstrand N. Bilateral electromyogram response latency following platform perturbation in unilateral transtibial prosthesis users: Influence of weight distribution and limb position. J Rehabil Res Dev. 2013;50(4):531-44. http://dx.doi.org/10.1682/JRRD.2012.01.0017

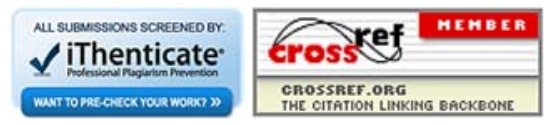

